\title{
EARTHQUAKE FORECASTING, PUBLIC POLICY AND EARTHQUAKE FORECASTING
}

\author{
G.J. Lensen*
}

\section{SYNOPSIS}

The geodetic, geophysical and seismological approaches to earthquake forecasting are summarised and illustrated with examples of precursory phenomena, which can be categorised into long term, intermediate term, short term and imminent. The results from at least two, but preferably more, disciplines are needed to reliably identify a precursory phase before a forecast can be made.

The socio-economic impact of earthquake forecasting on business and the community is discussed and it is recommended that for at least the present such forecasts should not be made public. Instead Civil Defence and related exercises should be held in several areas including the "prone" area, in a realistic manner, ensure that manpower is organised, equipment etc. upgraded, and public awareness sharpened in order to reduce the imminent effects on safety both in public and at home.

Once the public has gained confidence, not only in the reliability of such forecasts, but more specifically confidence in the authorities concerned, and once their preparedness has become an accepted fact, only then will a public forecasting have a beneficial effect.

\section{EARTHQUAKE FORECASTING}

The earth is subjected to forces which produce strain in its crust. This strain is accumulating continuously until the yield strength of the crust (ultimate strain) in any one area is reached. At that stage the potential energy of the accumulated strain transforms into the kinetic energy of the moving mass involved in the earth shift, into heat and into energy of seismic vibrations. About 80-85\% of the kinetic energy is dissipated in shifting of the mass involved in the earth shift.

The rate of strain accumulation and the yield strength of the crust vary with time and place; the major contrasts are found between regions with different tectonic regimes of tension, shear and compression.

As strain accumulates the earth's crust deforms semi-elastically, resulting in changes in shape and elevation, the former causing rotation and changes in surface shape, the latter causing tilt.

Prior to strain release during an earth shift the secular trend reverses and forms the precursory phase in earth deformation. The trends of the three important phases can be summarised as follows:

$\begin{aligned} & \text { Change in secular precursory } \\ & \text { vertical up }\end{aligned} \begin{aligned} & \text { upth shift } \\ & \text { plane down }\end{aligned}$ down up
horizontal dextral sinistral dextral
plane sinistral dextral sinistral
The surface changes can be monitored

* Earth Deformation Section, N.Z. Geological Survey, D.S.I.R., Lower Hutt. geodetically, by means of tide gauges and by tilt measurements. Some examples are given in Figs 1,2 and 3 , and in Table 1.

The following relationships for crustal earthquakes in any one tectonic regime can be postulated.

(1) Precursory deformation is in a sense opposite to that of secular deformation.

(2) The amount and duration of precursory deformation are proportionate to the magnitude of the earthquake.

(3) The area affected by precursory deformation is proportional to the magnitude of the earthquake.

(4) The amount and duration of precursory deformation varies inversely with the distance from the hypocentre.

The surface changes in shape and elevation result from the same causes as changes within the crust, some of the most important of which are changes in shape, orientation and volume of pore spaces which result in changes in several geophysical properties dueing a cycle of earth deformation.

The change in resistivity is perhaps the best documented. The conductivity of electric pulses in the near surface saturated rocks changes by 10-15\% prior to moderately large earthquakes. Fig. 4.

Other changes in geomagnetic field, piezoremanent magnetism, telluric currents, etc., have been proposed but have as yet not been substantiated sufficiently.

Precursory changes in watertable and temperature, and changes in oil flow, obviously related to changes in pore space have been clearly demonstrated in several instances. 


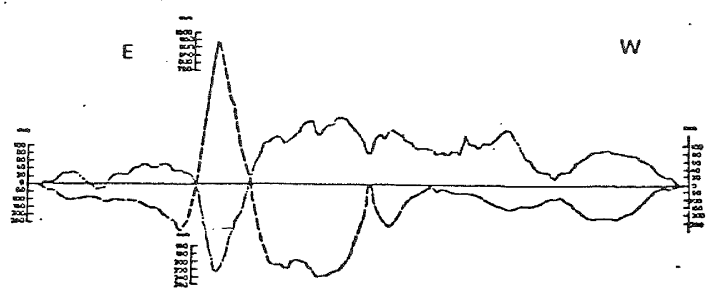

FIG. 1 A $100 \mathrm{~km}$ long precise levelling route along Muroto Peninsular on the South Coast of Shikoku was monitored in 1895, 1935 and 1947; the major Nankaido earthquake occurred in 1946. The dotted line showing the changes in height from 1895-1935 and the dashed line (1935-1947). which includes the 1946 earth shift, reflect a mirror image. Areas that went down before the earthquake, elevated during the earthquake and vice versa. (Miyabe, 1954).
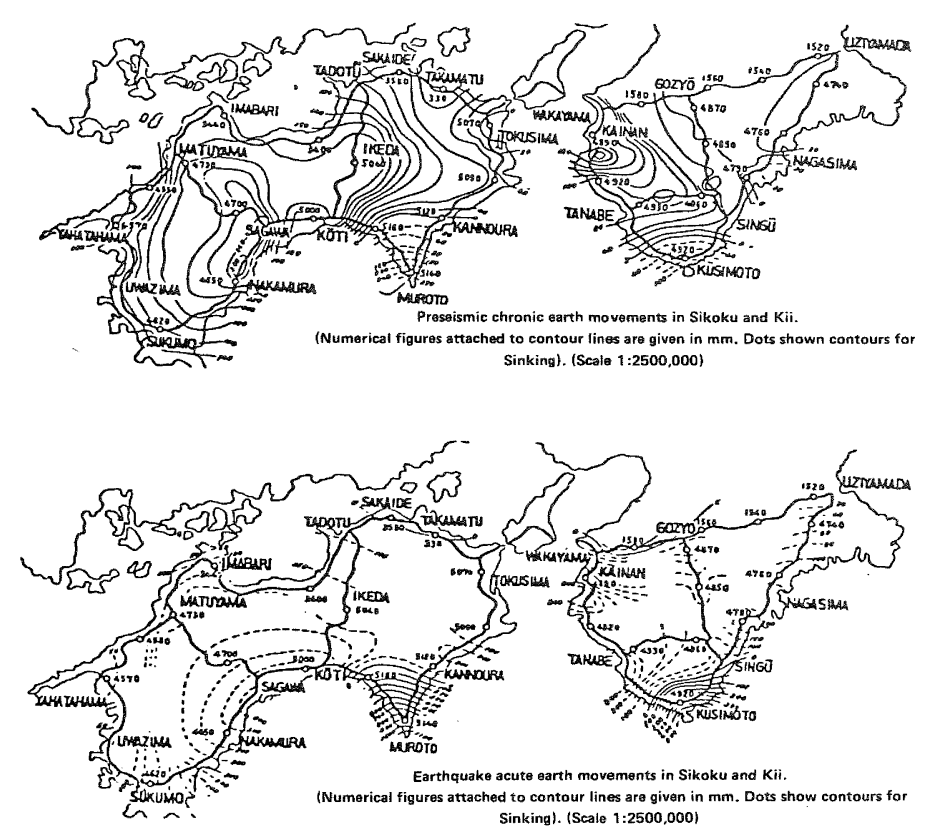

FIG. 2 This reversal was regional and effected not only Muroto Peninsular but the entire island of Shikoku and aiso Kii Peninsutar. (Miyabe, 1954).
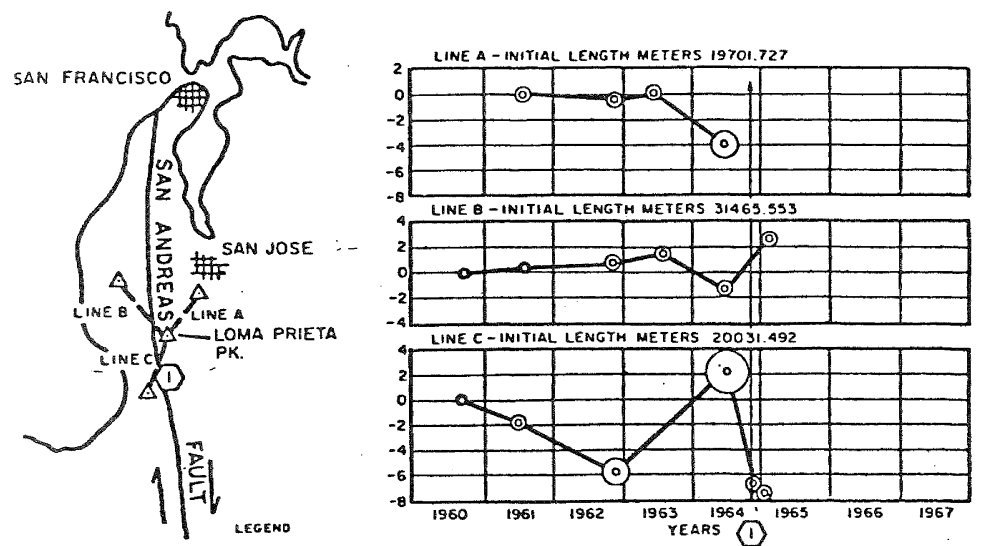

(C) PRobable ERROR INDICATED BY DIAMETER OF OUTER CIRCLES

(1) Corralitos Earthouake, NOVEMBer 15,1964, MAGnitued 5.2

(1) EPICENTER OF CORRALITOS EARTHQUAKE

FIG. 3 Demonstrates that the nature of horizontal deformation, as indicated by arrows along the San Andreas Fault, changes in the precursory phase. Line $C$ which normally shortens, - at least Andres Falt, chanes in the $p$ lengthens, shortens in the precursory phase. The precursory phase is opposite of both the lengthens, shortens in the precursory phase.
secular and earth shift phases. (Hoffman 1968).

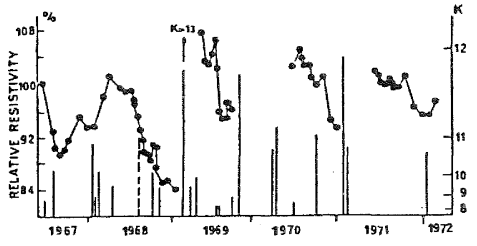

FIG. 4 Demonstrates resistivity changes precursory to moderate earthquakes (K13= M5.5) in the Garm region in S.E.Siberia, (Barsukov, 1974). 


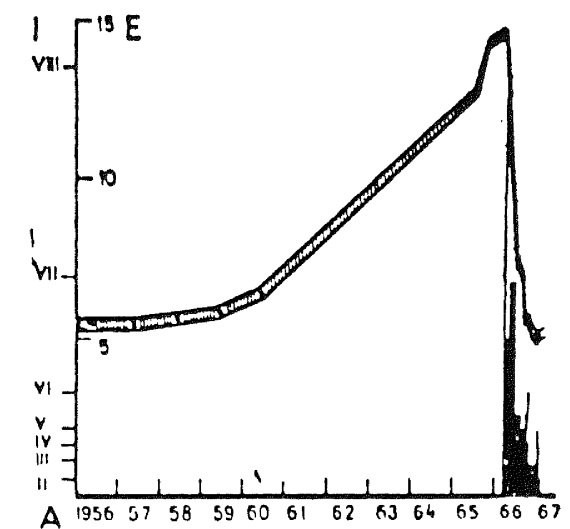

Precursory change in radon content of mineral water starting about 1961 heralding the Taskent earthquakes in 1966. (Sadovsky et al., 1972).

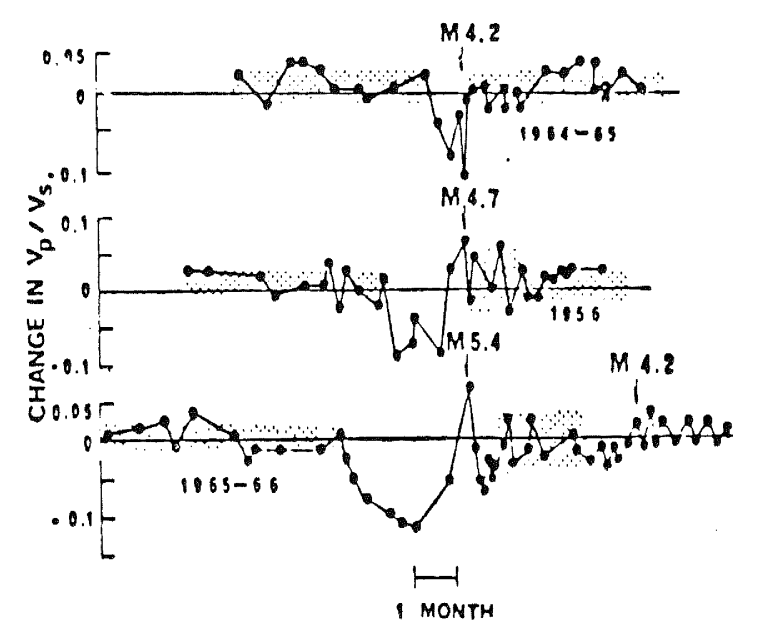

Fig. 8 Shows 3 examples of short period changes in $V p /$ $V s$ ratios preceding 3 small earthquakes in the Garm region in S.E. Siberia. Note the precursory time increases with the earthquake magnitude. (Afer Semyenov, 1969).

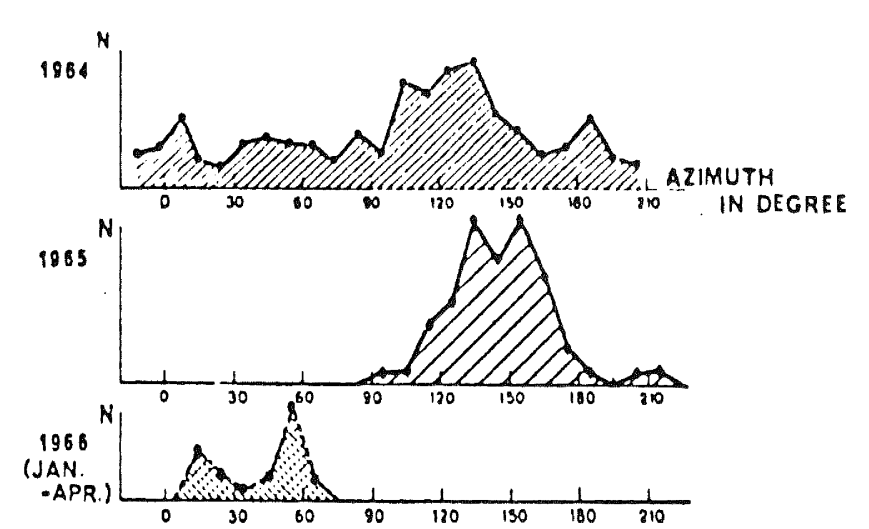

Shows the changes in azimuth of compressional axes derived from fault plane studies. In 1964 the azimuth distribution is still relatively random. In 1965 this has changed to a $150 \%$ preference, while those of early 1966 (earthquake April 1966) have flopped through $90 \%$ to about $060 \%$, suggesting two precursory phases.

(Sadovsky et al., 1972).

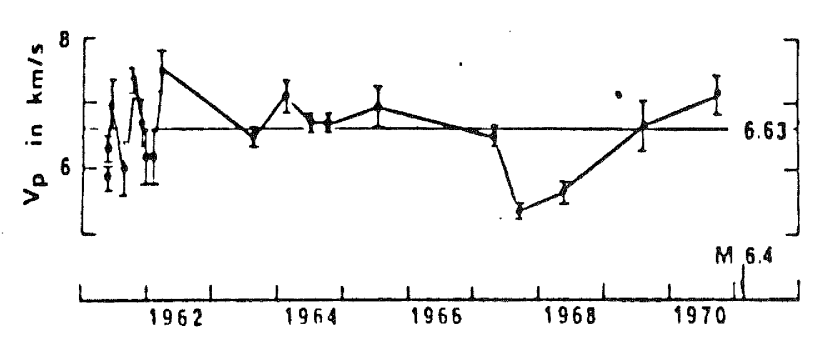

Shows the post 1967 decrease in $V p$ velocity which returns to normal by 1970. The earthquake occurred in 1971 in San Fernando in California. (Whitcomv et al., 1973). 
Precursory changes in radon emission - a radioactive gas with a half life of 3.5 days present in some mineral springs have also been reported several times. Fig. 5.

The monitoring of all these changes depends to a large extent on variables such as "noise" levels and the favourable presence of water, oil or radon.

Seismic changes also occur and range from changes in seismic activity patterns to changes in seismic properties of the earth's crust. Approaches to forecasting in this field are numerous and most can be substantiated at one time in one area, but do not necessarily hold at other times of in other areas.

The simplest approaches can be grouped in the "statistical or probability prediction" category; which varies with the statistical or mathematical elegance in the use of extreme value theory, distributions à la Gauss, weibull etc. etc., but have the basic underlying philosophy: "The further away from the last big one, the nearer the next one". The basic assumption is that the data base available is of a time length sufficiently long to justify extrapolation into the future and that to all intents and purposes seismicity is a process that continues at a relatively uniform rate. This is not the case, as several workers have clearly demonstrated that seismicity is episodic and is interspaced with periods of relative seismic quiescence of equal or longer length. Where an area is at present and in the historic past seismically quiet, the geological evidence should be used to evaluate its average seismicity.

More promising are the studies into changes in seismic properties. The compressional axes derived from first arrivals studies based on small (local) earthquakes show remarkable changes in azimuth prior to a relatively major earthquake. Fig. 6. However, not everywhere and not always do small shocks occur prior to major earthquakes. Paradoxically several approaches use the absence of seismic activity (seismic gap) prior to major earthquakes as a precursory indicator.

Changes in seismic wave velocities can either directly (Fig. 7), or indirectly by means of Vp/Vs ratio (Fig. 8) be used as precursory indicators. In both methods a precursory drop in $\mathrm{Vp}$ velocity or a decrease in ratio followed by a return to normal precedes the earthquake.

While the aforegoing discussion deals with precursory phenomena that can be observed and verified instrumentally, there is a further group of phenomena which have been reported throughout historic time, but which cannot be evaluated instrumentally, have no scientific explanation at present and are therefore still often regarded as improbable. The author however has no doubt that such phenomena exist and can be used, because of their short lead times, to herald the imminent earthquake. These phenomena include abnormal animal behaviour in which different species display different precursory times - and can ambiguously be called "Prescience-phenomena".

Different approaches detect precursory anomalies of different duration before an earthquake. While this may seem a disadvantage it is in fact a real advantage. While an $\mathrm{M} 8$ earthquake may geodetically be detected 20 years before the event, at the time of detection it is not known that an earthquake of that particular magnitude is developing. Although continuous geodetic monitoring is theoretically possible it is impractical. While long, intermediate and short term periods can be covered by repeated observations, short and imminent term approaches need to be used to herald the event. The precursory time of different groups of methods are shown below:

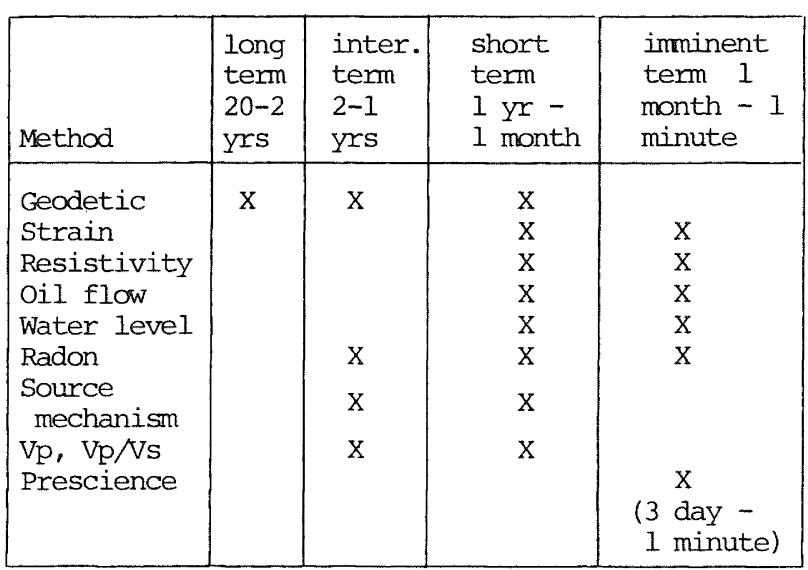

As stated before for various reasons most approaches do not work all the time. The geodetic approach would appear the most reliable as the author does not know of any case where it can be demonstrated that this approach has failed. However there are some suggestions that precursory deformation identified geodetically need not necessarily be followed by an earthquake and may be attributed to rather large fluctuations in secular behaviour. It is thus essential that any precursory indications detected by one approach prior to accepting an earthquake forecast as such.

\section{SHOUID AN EARTHQUAKE FORECAST BE MADE PUBLIC AND WHEN?}

Dr Carl Kisslinger, President of the American Geophysical Union, is quoted in Nature (1979, p.421) as stating that:

"the mayor of Pinotep Nacional in Mexico has claimed that public reaction to an earthquake forecast by U.S. scientists did more damage to the economy of his town than the 7.5 magnitude shock that hit the area last August".

This statement puts the first half of the problem in a nutshell. The half, not stated, is the answer to the question:

"did the forecast save human lives?"

The problem is thus twofold and both involve interests that are diametrically opposed, they clash.

The economic aspects of earthquake forecasting have both direct and indirect effects. These are many and do not require any imagination. After a forecast has been issued for a specific region construction in progress will cease and new construction will be postponed. The flow of investment capital in the region will cease and will be withdrawn, which in turn will depreciate real estate values. All of these factors will reduce 
the demand for labour and retailers and wholesalers will suffer accordingly. Another effect is withdrawal of labour by individuals moving out of the prone area. Why should this be so?

It is significant that the Maoris have no legend or traditions relating to earthquakes. This is certainly not because earthquakes did not occur in New Zealand prior to the arrival of the pakeha.

To the Maori the effects of a major earthquake were no different from those of a storm. In both cases his hut might be demolished but all that was required of him was to poke his head through the raupo and climb out. The incident left thus no lasting impression. His design of building was in harmony with the environment.

With the arrival of the pakeha new, more efficient and expedient construction methods and materials were introduced. The desire to construct a more permanent (?), insulating and more light introducing and aesthetically but not necessarily more ethically pleasing designs thrived. Add to this increasing land values, which forced construction upwards rather than sideways, together with the desire to keep the services from spreading too far, and the present configuration of population centres, which are, in disharmony with the environment, resulted. Society has collectively, either through ignorance or otherwise, succeeded in constructing its own death traps.

The problem from both aspects - that of avoiding an economic depression and that of saving human lives - cannot be solved at the time of such a forecast, but should be dealt with now. The knowledge that a destructive earthquake will happen irrespective of whether it is forecast or not, should guide us.

Literature on the socio-economic aspects of earthquake forecasting has already proliferated, but little is of practical use. problem:

There are three possible approaches to the

(1) Do nothing and call the earthquake an Act of God - Prof. N. N. Ambraseys of Imperial college in discussing earthquake prevention has answered this attitude appropriately - an Act of God yesterday has, because of increased knowledge, become an act of criminal negligence today.

(2) Accept the present hazards as a "fait accompli" and try to deal with the untold number of socio-economic problems that it has created. So far this approach has shown little success.

(3) Improve the present situation by reducing the hazards as far as our knowledge permits and is humanly possible - this will automatically reduce the socio-economic problems that were created to a minimum and can therefore be dealt with much more easily.

The last approach is here preferred and the following practical steps are suggested:

(1) Replace all buildings of non-reinforced masonry construction of pre 1935 vintage the local bodies are already required to do so, but most local councils have postponed with monotonous regularity the execution of this directive.

(2) To survey all buildings which, in the light of present and future knowledge, may be suspected of constituting earthquake hazards and the recommendation of such a survey should be acted upon mandatory.

(3) Although in New Zealand our building by-laws and code of practices are relatively good compared with overseas the "by-laws" are not mandatory - they should be made so.

(4) To intensify research into improved design, methods and materials; the results should be incorporated in revised building by-laws etc

Once the public at large is confident that these and other possible steps to safeguard life are implemented, the degree of economic depression resulting from an earthquake forecast will be greatly reduced. However it will also be necessary:

(5) To run a regular general public education programme, at short intervals, on what to do and what not to do during and after an earthquake on a practical level. Ordinary simple lessons learned from previous earthquakes such as "jumping out of bed, cutting one's feet on broken glass and then stepping into boiling water escaped from the severed hot water cylinder" - Inangahua 1968 earthquake (remedy: have bedroom slippers and torch handy), are very important and will create confidence in the public that they themselves become capable to handle the earthquake at their own individual level and setting.

(6) Finally, the present Civil Defence is geared to prepare for - and go into action after the event of an earthquake. Its scope should be widened to include preparations to deal with the immediate effects resulting from an earthquake forecast.

There is no doubt in my mind that earthquake forecasting would also strengthen the Civil Defence and facilitate materially and from a manpower point of view its organisation (the general apathetic attitude of 'what is the sense of preparing for an earthquake which may not even come in my lifetime' would be miraculously cured by the knowledge that a destructive earthquake is coming soon). The subsequent effectiveness and efficiency of Civil Defence would be greatly enhanced. This in return would again increase public confidence considerably.

I have no doubt that the basic underlying concept of drastically reducing the hazard potential will be decried as economically impractical. My answer to this is: in the short term yes, in the lony term definitely No.

\section{SUMMARY}

Considering the hazards present in all communities and considering that earthquake forecasting is still in its infancy and false alarms must be expected it is recommended that the first few forecasts not be made public. Instead Civil Defence and related exercises be held in several areas - including the "prone area" - in a realistic manner in order that manpower will be organised, equipment, etc. upgraded and public awareness be sharpened to reduce the imminent effects on safety both in public and at home. 


\section{BIBLIOGRAPHY}

Barsukov, O.M., 1972, "Variations of Electric Resistivity of Mountain Rocks Connected with Tectonic Causes". Tectonophysics, 14: 273-277. Hoffman, R.B., 1968, "Geodimeter Fault Movement Investigations in California". Bull. Dept Water Resources, State of California, No. $116-6$.

Lensen, G.J., 1974, "On the Nature of Vertical Deformation and on the Frequency of Earth Deformation in General". Tectonophysics, 23: 391-406.

Mayabe, N., 1954, "Vertical Earth Deformation in Nankai District". The Geographic Survey Inst., 4: 1-4.
Sadovsky, M.A., Nersosov, I.L., Nigmatullaev, S.K., Latynina, L.A., Lukk, A.A., Semenov, A.N., Simbireva, I.G., and Ulomov, V.I., 1972, "The Processes Preceding Strong Earthquakes in Some Regions of Middle Asia". Tectonophysics, 14: 295-307.

Semyenov, A.N., 1969, "Variations in the Travel Time of Transverse and Longitudinal Waves Before Violent Earthquakes". Izv. Acad. Sci. U.S.S.R., 4 : 245-248.

Whitcomb, J.H., Garmany, J.D., and Anderson, D.L., 1973, "Earthquake Prediction: Variation of Seismic Velocities Before the San Fernando Earthquake". Science, 180: 632-635.

This paper was presented at the South Pacific Regional Conference on Earthquake Engineering held in Wellington on 8, 9 and 10 May, 1979.

\begin{tabular}{|c|c|c|c|c|c|c|c|c|c|c|}
\hline \multirow[b]{2}{*}{ Date } & \multirow[b]{2}{*}{ M } & \multirow[b]{2}{*}{$\begin{array}{l}\text { Depth } \\
(\mathrm{km})\end{array}$} & \multirow[b]{2}{*}{ Locality } & \multicolumn{2}{|c|}{ Secular $\alpha$} & \multicolumn{2}{|c|}{ Precursory $B$} & \multicolumn{2}{|c|}{ Earthshift } & \multirow{2}{*}{$\begin{array}{l}\text { Epic. } \\
\text { dist. } \\
\text { (km) }\end{array}$} \\
\hline & & & & $\begin{array}{c}\text { pre } \\
(\mathrm{mm} / \mathrm{yr})\end{array}$ & $\begin{array}{c}\text { post } \\
(\mathrm{mm} / \mathrm{yr})\end{array}$ & $\begin{array}{l}\text { amount } \\
\text { (cm) }\end{array}$ & time & $\begin{array}{l}\mathrm{V} \\
(\mathrm{cm})\end{array}$ & $\begin{array}{c}\mathrm{H} \\
(\mathrm{cm})\end{array}$ & \\
\hline $\begin{array}{l}1331-8-15 \\
1703-12-31 \\
1707-10-28\end{array}$ & & & $\begin{array}{l}\text { Senrigahama } \\
\text { Kanto } \\
\text { Nankaido }\end{array}$ & & $\begin{array}{l}- \\
\overline{-} \\
+\end{array}$ & & & $\begin{array}{l}+ \\
+ \\
+200 \\
-100\end{array}$ & & \\
\hline $\begin{array}{l}1793-2-08 \\
1802-12-09\end{array}$ & 6.9 & & $\begin{array}{l}\text { Adigasawa } \\
\text { Sado }\end{array}$ & & & $\begin{array}{l}+100 \\
+100\end{array}$ & $\begin{array}{l}4 \mathrm{hrs} \\
4 \mathrm{hrs}\end{array}$ & $\begin{array}{l}+300 \\
+>200\end{array}$ & & $\begin{array}{l}12 \\
10\end{array}$ \\
\hline $1872-3-14$ & 7.1 & & Hamada & & & +200 & $\frac{1}{2} \mathrm{hr}$ & +500 & & 5 \\
\hline $1894-6-20$ & & & Tokyo & +4 & & -3 & $>7$ yrs & -4 & & \\
\hline $1909-8-14$ & 6.0 & & Anegawa & & & 4 & $<10$ yrs & -15 & & 25 \\
\hline $1923-9-01$ & 7.9 & $10-20$ & Kanto & -10 & -8 & +10 & 3 yrs & +200 & d600 & 50 \\
\hline $1926-8-03$ & 6.2 & & Haneda & & & & $<3$ yrs & -70 & & 10 \\
\hline $1927-3-07$ & 7.4 & & Tango & & & +150 & $2 \frac{1}{2} \mathrm{hrs}$ & +90 & s310 & 15 \\
\hline $1927-10-27$ & 5.4 & $<10$ & Sekihara & & & +2.7 & $<33$ yrs & +21 & & 10 \\
\hline $1928-5-21$ & 5.8 & 60 & Tokyo & +2 & & -18 & 0.3 yrs & -56 & & 10 \\
\hline $1930-11-04$ & 5.2 & 10 & Ito & & & +10 & $<7$ yrs & +122 & $\begin{array}{l}\text { s350 } \\
\text { d120 }\end{array}$ & 40 \\
\hline $1943-9-10$ & 7.4 & 10 & Tottori & & & + & $<2$ yrs & +75 & d150 & 60 \\
\hline $1946-12-21$ & 8.1 & & Nankaido & -7 & -5 & + & $1 \mathrm{yr}$ & +95 & & 150 \\
\hline $1948-6-28$ & 7.2 & 14 & Fukui & & & + & $\frac{1}{2}$ yr & +50 & sl00 & 40 \\
\hline $1964-3-28$ & 7.7 & $10-20$ & Niigata & $\begin{array}{l}+4 \\
-2\end{array}$ & & + & 8 yrs & $\begin{array}{l}-\quad 20 \\
+600\end{array}$ & & 25 \\
\hline
\end{tabular}

Table 1.

Shows that the vertical precursory deformation is in a sense opposite to the secular but the same as that of the earth shift trend. (Lensen, 1974) 